\title{
Reflections on Regards Hybrides, an International Forum (2019, Second Edition) ${ }^{1}$ Douglas Rosenberg
}

Keywords: screendance, Regards Hybrides, allyhood, diversity, generational shift

While in Montreal recently, I had the opportunity to see and experience a profoundly moving video installation at the Musee Contemporain, by the artist Francis Alÿs. ${ }^{2}$ Alÿs' work is poetic, political and often addresses his own quotidian observations of everyday life through performance, sculpture and installation. He describes his practice as "a sort of discursive argument composed of episodes, metaphors, or parables." In Children's Games, the multi-screen installation at Musee Contemporain, Alÿs arrays almost twenty individual films shot and collected since 1999 into a porous tapestry of childhood activities; an inventory or index of children at play shot around the globe. These simple films collectively illuminated the ways in which mostly impoverished children turn everyday objects such as stones, plastic bottles, flying insects, chairs, coins, and stones into games and a sort of interactive universe. What was evident in all the films, was the idea of improvisation and of giving space to one's collaborators in order to create a collective sense of freedom and joy. While wandering through the cinematic landscape created by the work of Alÿs, I began thinking about how we are taught (or instinctively learn) to take turns, and to give space to others so that others may experience something joyful or new in their lives. As artists, we compete throughout our careers; for shows, for space in shows, for reviews and teaching positions, for performance opportunities and grants and for gigs of all kinds. It becomes rote, this competition for space, for a platform from which to speak.

However, space like land, is limited and needs to be tended. While it seems there should be enough for everyone, the idea of taking turns or sharing such space has gotten lost both in the metaphoric sense and in reality as well. I've been thinking a lot lately, about what it means to share one's resources, to really share space and things and platforms and opportunities; to be generous in a way that is neither done for one's own edification or attention or for personal gain, but simply as a gesture of recognition. I've been thinking about what it means to be an ally in the arts and beyond and how to do so generously and with an open heart. Advocating for those other than oneself inherently means that an opportunity for visibility may confer to the one we advocate for, rather than to ourselves. This seems to be a foundational and very real fact of generosity. 


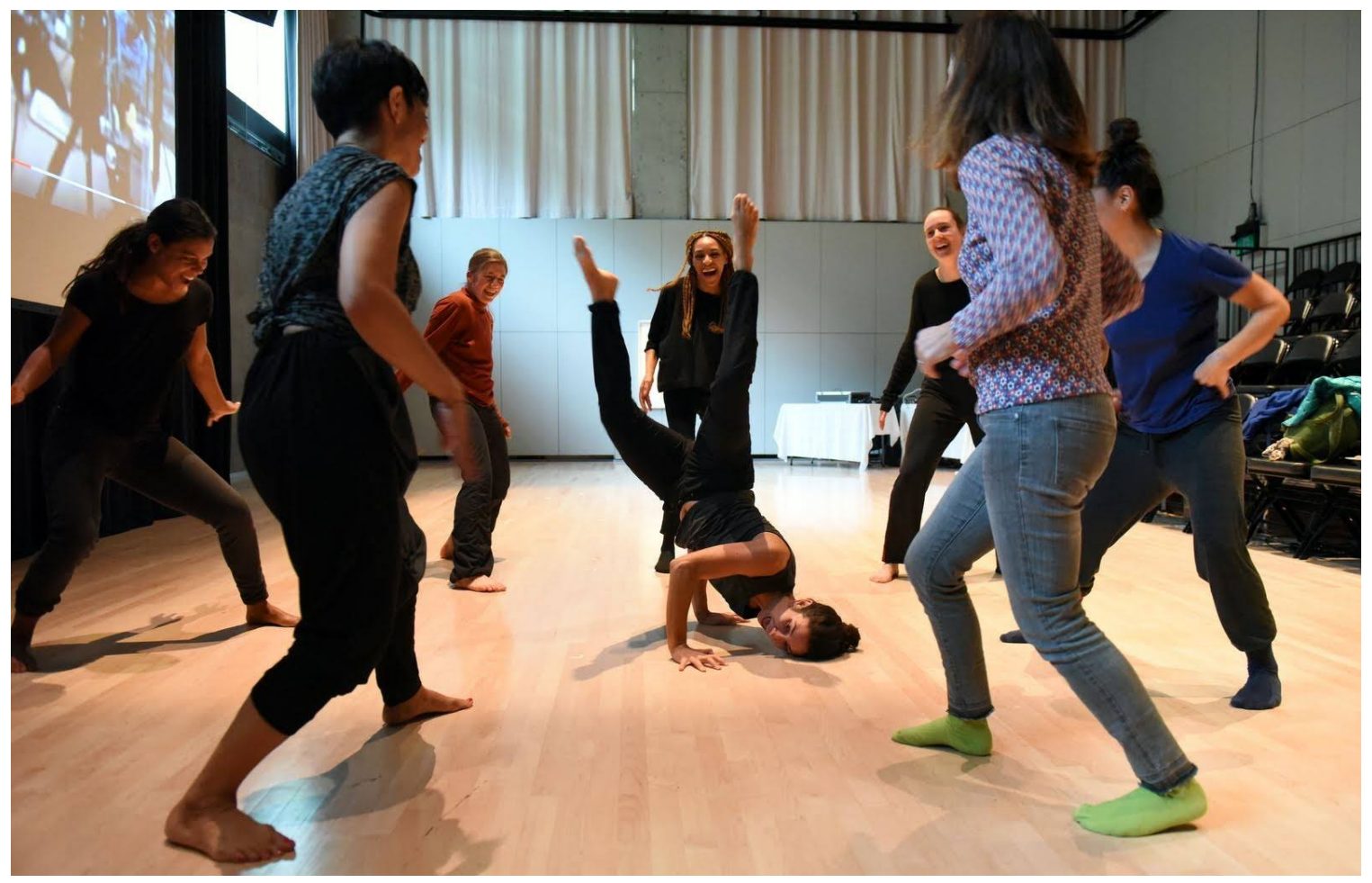

Participants at Regards Hybrides Photo: Omer Yukseker

I have been noticing more and more, that spaces in which I regularly participate, conferences, publishing, symposia, public exhibitions and other spaces where knowledge or creative capital is shared, have a new and different dynamic. Simply put, many of these spaces have become sensitive to the changes in social and cultural norms (many have not) that lean toward inclusivity, polyvocality and diversity. They have become aspirational spaces in which one can feel the pendulum swing of a process of repair and righteousness, where discussions of privilege and otherness are brought from the margins to the center. I recently had the opportunity to attend Regards Hybrides, an International Forum focused on screendance, and curated by Priscilla Guy and Emilie Morin at Montreal's TangenteDanse. Regards Hybrides felt charged with a particularly contemporary and thoughtful energy. Contemporary dance artist Kim-Sanh Châu describes the organizing principles of Guy as "definitely engaged in a feminist curation, which by extension involves BIPOC and Queer artists", which, she notes, "is not usual in the screendance world." However, such a gesture is perhaps signaling a significant change in the landscape of the field. Since attending Regards Hybrides, I have been thinking about a generational shift in the field and the possibility for a kind of "allyhood" in support of an inclusive screendance community. 
Over the few days of screenings and panels, I was hyper-conscious of my own body in that space, how I took up space, how I processed the very curatorial imperative of the event and what that might mean on a deeper level generally. As colleagues presented papers, screened films and performed in real and virtual space, and as a non-French speaker, I listened to all the proceedings in simultaneous translation from English to French. The lag in the translation and the difficulty that the translators often had with the very specific use of language to describe complicated theory seemed like an apt metaphor for my own feelings of being outside of the discourse I was there to participate in. I felt self-consciously like an interloper in the room and in many of the discussions. Rightly so, as the curatorial imprimatur was decidedly feminist, of color and queer. Though an empathetic ally, I am none of the above. I wondered, can I speak? May I speak here? If I do, whose space do I impose on? And of what value is my voice in this discussion? For the most part, I tried to listen and to feel what that was like to be not in the center, but at the margins, a visitor in a space that was empowering others by intention and to be conscious of the amount of space I take up, generally.

Clearly, we are well into a moment in which many of us need to lean out so others can lean in. This means not only being an ally, but advocating strongly for spaces that are inclusive and empowering, consciously recognizing issues of gender and sexuality, marginalized identities and LGBTQ+ challenges. Here, I am a person in progress and realize that it is my time to listen more, to share the space and to generously be available if called on. I am conscious of the abundance of good fortune that has made it possible for me, through my work and the facts of my gender and personhood, to have a voice, and I am acutely aware that such privilege necessitates, in fact demands, working on behalf of others even if, and especially if, that work involves ceding space.

At the start of each session of the forum I attended in Montreal, a number of speakers read the following statement:

"I would like to begin by acknowledging that the land on which we gather is the traditional and unceded territory of the Kanien'keha:ka (Mohawk), a place which has long served as a site of meeting and exchange amongst nations."

This particular statement was pertinent to the venue that we were in of course, but one can imagine such a statement acknowledging the histories and personhood of other groups, who have been silenced, omitted or otherwise made absent from our own communities. As artists and problem-solvers, I imagine we can make such an activist gesture through the arts, and I wish to be a part of that gesture.

As I listened to the speakers and presenters at Regards Hybrides, I was aware of how the work of the scholars and artists who were presenting flowed from a distinctly personal, embodied set of life experiences. ${ }^{4}$ I took notes to memorialize my responses in the moment during the panels and presentations and in the months after the event, 
I reached out to some of the participants through email to help me flesh out my understanding of their ideas and to create some space here to share their insights. The email responses to my questions extended the event across distance and time in an uncanny way and the generous responses I received took me back to the same embodied experience I had while in the room in November. Further Skype conversations with Alanna Thain and Marisa Zanotti amplified the asynchronous nature of how we are able to continue to remain in conversation in and out of "real time", especially as the Covid-19 pandemic took hold and we were all to some extent, frozen in place, immobilized and unable to attend the sort of conferences and events in which such exchanges thrive. Many of my subsequent conversations with presenters seemed eerily prescient of the current moment though the murder of George Floyd and the ensuing global protests had yet to occur. In fact, many of the presenters at the Regards Hybrides event spoke to issues relevant to racial justice and equity in their original presentations.

Apropos of the current historical moment, in her talk at Regards Hybrides, Hilary Bergen talked about "post-human" dance (dance as mediated by technological transformation) and in a later correspondence pushed back a bit at the idea of "the personal" that I had attached to thusly, stating,

"I don't interpret the impact of the presenters' work as attributable to its personal nature so much as its investment in an embodied and relational politics. In the panel I participated on, where many of us addressed the relationship between race / gender and histories of technology, dance and film, the takeaway for me was the importance of being attuned to the political resonance of these bodies on screen, a resonance that extends beyond just the image of the body, to the discourses circulated about those images, and the histories that get buried along the way. I suppose the risk, for me, of viewing scholarship by a diverse group of presenters as "personal" first (even though it may well be!) is that it positions the white (or white/male) scholar as somehow apersonal or, like a blank canvas, exempt from the "distraction" of the personal." 5

Dance artist Anna Macdonald talked about loss and identity, brought on to some extent by the process of aging. In retrospect and in response to my subsequent prompts, she expanded on her own experience at the event and noted that, while aware of the difference she felt (generationally older, not a person of color, etc.), though she "felt at home in a way that is unusual for me at screendance events... the exciting bit for me is the permission 'otherness' gives for a range of work to be seen." She wrote, "I enjoyed that. I enjoyed the critical mass of other voices tipping so that they became 'the' voices". ${ }^{6}$ I also recall Macdonald's evocation of what she called, a "feminine cinematic esthetic" that seemed to bond her to the larger discussion raised by others in the language of feminism and feminist practices.

'The personal' is also part of a nascent discourse in black feminist practices as noted by Naomi Macalalad Bragin who talked about the intricacies of animating muscle groups and contraction in black dance forms such as popping and locking. She also 
spoke about a "Black feminist poethics", in the context of Black feminist speculative practices. Bragin explained that the scholar Denise Ferreira da Silva had used the term "Black Feminist Poethics" as the title of a 2014 journal article, and that her own current book project, Black Power of Hip Hop Dance: On Kinethic Politics, builds a theory of "kinethics", drawing on Ferreira da Silva's work.

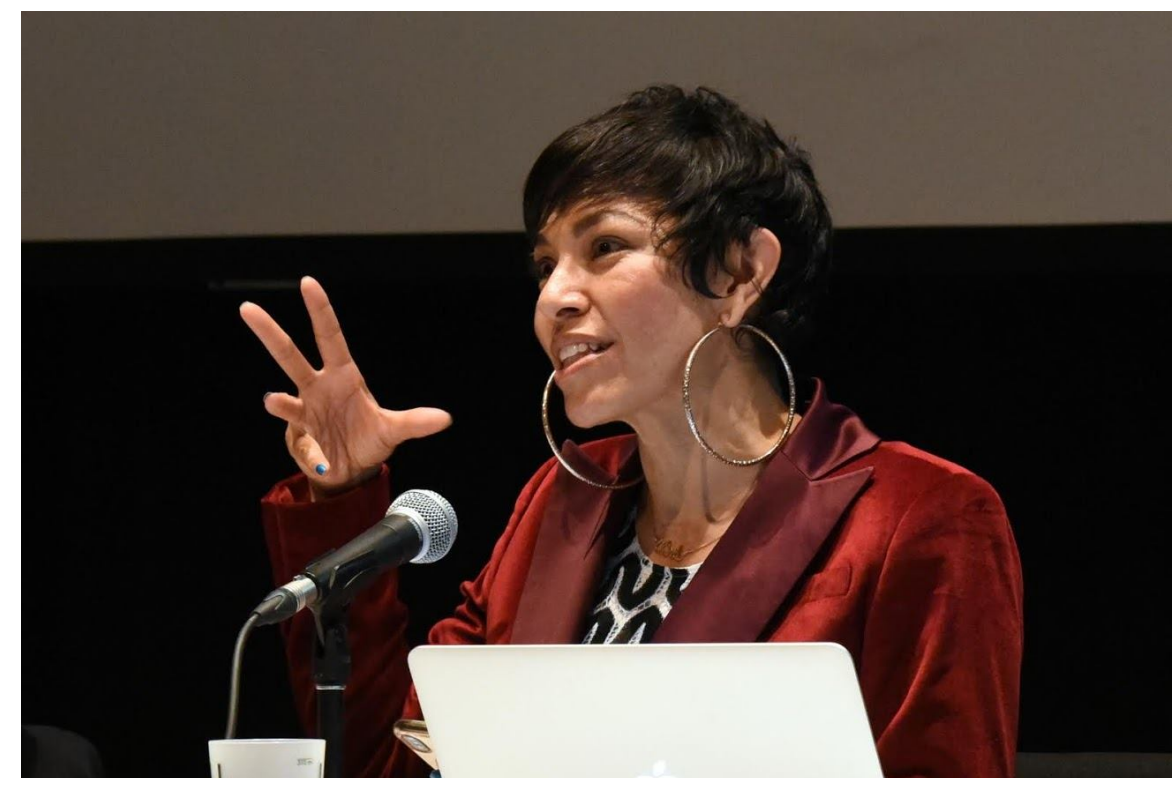

Naomi Macalalad Bragin, photo: Omer Yukseker

I was fascinated and enlightened by the films of First Nations artist Terrance Houle and moreso by his explanations of the symbolism and personal backstory leading up to his challenging and provocative work, which implicates the viewer in the very colonialization and subjugation that Houle unravels in his riveting and at times, troubling films. If I look away, am I even more complicit? The gaze is imminently political here.

In her talk, artist and scholar Ayanna Dozier, spoke about the complex and existential questions that flowed from the groundbreaking work of Janet Jackson. Of particular impact to me was the Dozier's deconstruction of what she called "the stare": Janet Jackson's uncanny move that quite literally stops the performance at a moment in which the performer wishes to amplify a sense of power or control over her audience. It was palpable when Dozier played back a concert video in real time, counting the minutes of silence and confrontation that turns to discomfort at times and upends the expectations of "liveness" in many ways. As there were multiple references to "poetics" by presenters, I asked Dozier (in a recent email conversation), to further explain some of the ideas she spoke about in Montreal and she wrote, 
My use of the term poetics is informed and transformed by Black feminist thought. I deploy Black feminist poetics in my scholarship as work that imbues a feeling of possibility and emancipation in its form. Its 'narrative' arc (understood here in its formal definition rather than its representative one), structure, and presentation move us outside the dominant epistemological position of Black womanhood as a point of negation in the world. ${ }^{7}$

Such conversations and densely theoretical disruptions create fissures that allow for new ideas to take root; in communities of caring, creative people and in the dominant narratives that we inherit in screendance and elsewhere.

In the seminar, film theorist Alanna Thain wondered aloud "why don't we reconceive the histories of cinema as the history of screendance?", a proposal with which I agree completely; indeed, why not? In our subsequent conversation, Thain suggested a number of ideas for me to consider in the context of this essay that both validated some of my observations and challenged me to move beyond my own limitations or boundaries in thinking about difference and community. She talked about the idea of "redistributing vulnerability" around such fraught issues as race and gender (in screendance and elsewhere) which I understood as a kind of communal embodiment of the anxiety around such conversations. She suggested that within "intergenerational conversations" we might find generational allyhood, and new kinds of professional practices leading to a model of "active engagement". ${ }^{8}$

While watching live, hybrid performances by Kim-Sanh Châu, Emilie Morin + Ryan Clayton, and Andrew Turner (Canada), all of which were predicated to some degree on corporeal / technological interfaces, it occurred to me that the issues raised by the artists who presented their "live" work in the context of Regards Hybrides, made those presenting graciously vulnerable: to viewers, to the technology and to scrutiny from an audience who wanted to know more about how to embody the questions such performative work raises in the context of screendance. They made themselves vulnerable to the failure of technology, of mediation generally, and their audience accommodated that risk, a gesture that I made a note to remember.

On screen, in real time, in slow motion, in digital media and in the space of the internet, I noted that, as an audience member, I was regarding the experience of others, often through digital mediation. I wondered if the artists and performers considered themselves as a part of history or apart from their historical predecessors? In response to that question, Kim-Sanh Châu said (via email) "I think artists tend to not detach themselves from predecessors, as it's part of inspiration, on a creative and reflective perspective. However, in dance, this can't be as true as other practices (literature, visual arts mostly) as dance is [at] its essence ephemeral." ${ }^{9}$ In regard to the question of historical predecessors, Châu also notes affiliations with visual artists, (Olafur Eliasson and James Turrell) filmmakers and philosophers (David Lynch and Timothy Morton). Her observations about the interdisciplinary work she presented at 
Regards Hybrides, speak to existential questions about the form itself. She states, "Space and time have always been an underlying obsession for dancers, at least it is for me... the question about space also relates to the question of what is real, or what kind of realness to do we allow to exist."10

In their work, Skype Duet, Emilie Morin + Ryan Clayton, performed across digital space in a way that seems now, eerily prescient; they appeared (she live, in the space of the audience, he as a screenic apparition) socially distanced, the technology of their interface transparently obvious, yet their engagement was suffused with warmth, humor and affection, If there was a technological lack in the form of the work, it did not seem to otherwise hamper a humanist sense of connection between the performers. I asked Morin + Clayton a number of questions via email to get a sense of how they saw their work within the context of both Regards Hybrides and the generational moment of screendance.

DR: Do you see art as agent for change?

Morin + Clayton: We see ourselves and our artistic inquiry as part of the dominant culture - a narrative with a capital "N". Aware we live within this dominant culture, our work contributes in its humble way to its critique. We are an agent of change in that we are interested in critiquing and transforming this narrative. There is more and more space in the public discourse for more diverse artists to raise their concerns. These alternative voices are becoming more visible within academia and the art industry. Despite that we are not directly addressing these narratives within our performance, but we are thinking of these other voices as we make our contribution ${ }^{11}$

DR: What is hi tech/lo tech?

Morin + Clayton: This question is one which cannot have a consistent answer but rather is framed by both the audience and performers context of technology... We think low tech means it's part of the audience and performers everyday, not a special magic trick reserved for the rich and technically proficient. ${ }^{12}$

DR: What is the right work and for which audience?

Morin + Clayton: We think a responsible part of the choreography of a performance is thinking through to whom the performance is addressed. Skype Duet was choreographed with a contemporary art / dance audience in mind, this is not to gatekeep the performance. We think any person from any audience would gain meaning from the performance but the attention of our intended audience is attuned to the ways in which our performance makes meaning. ${ }^{13}$

I saw in notes that I had written to myself a personal reminder that speaks to screendance as a space of empowerment, that is writing its own history through deep engagement with significant questions about the field and its politics. The division of 
labor in the screendance community is largely female but the distribution of equity is neither adequately acknowledged nor rewarded equally. While there are numerous digressions in any timeline or index of screendance as an artform and as a space of intellectual consideration, the history of screendance is a feministhistory as Guy's event demonstrates and even more, I would claim, flows through the legacies of feminist theory, its practices and political ideology. Throughout the programming by Guy and her guest curators, including Alanna Thain, Claudia Kappenberg, Ximena Monroy and Paulina Ruiz Carballido, we were reminded of that fact through the presence of work by Amy Greenfield, Maya Deren, Lucy Cash, Marisa Zanotti, Katrina McPherson and others; work that, while generational and straddling numerous eras, encourages us to be empathetic and present as viewers. It is a reminder of what generational allyhood looks like in practice.

Taken as a whole, the presenters, curators, scholars and artists asked us to be not so much a woke community (if woke is still a thing) but a community that is actively and constantly in the process of awakening to the changes in the cultures we inhabit, to the re-understandings of our histories and to the possibilities of an egalitarian and significant contribution that screendance can make to such a dialog.

In organizing Regards Hybrides, an International Forum, Artistic Director and Curator Priscilla Guy has created a context for understanding not only the current climate of a generational shift in screendance, but her hybrid event pushes us toward a new model. Activist curated programs by artists / curators /educators such as Cara Hagen, inclusive programming of work by indigenous artist and filmmaker Terrence Houle, boundary crossing theory by scholars including Naomi Macalalad Bragin and Ayanna Dozier and others, resonate with a new cultural understanding of the pendulum swing away from a dominant narrative in screendance. Such visionary and intellectual work creates a new audience of allies whose collaborative task is to bear witness, as work that previously lived at the margins of screendance now occupies the center in ways that make us all students. It awakens us to what an inclusive and aspirational community looks like, such as the one suggested by the artist Francis Alÿs in the aforementioned multi-screen installation at Montreal's Musee Contemporain. His Children's Games models hope, community and generational optimism through a seemingly simple world of children's games. 


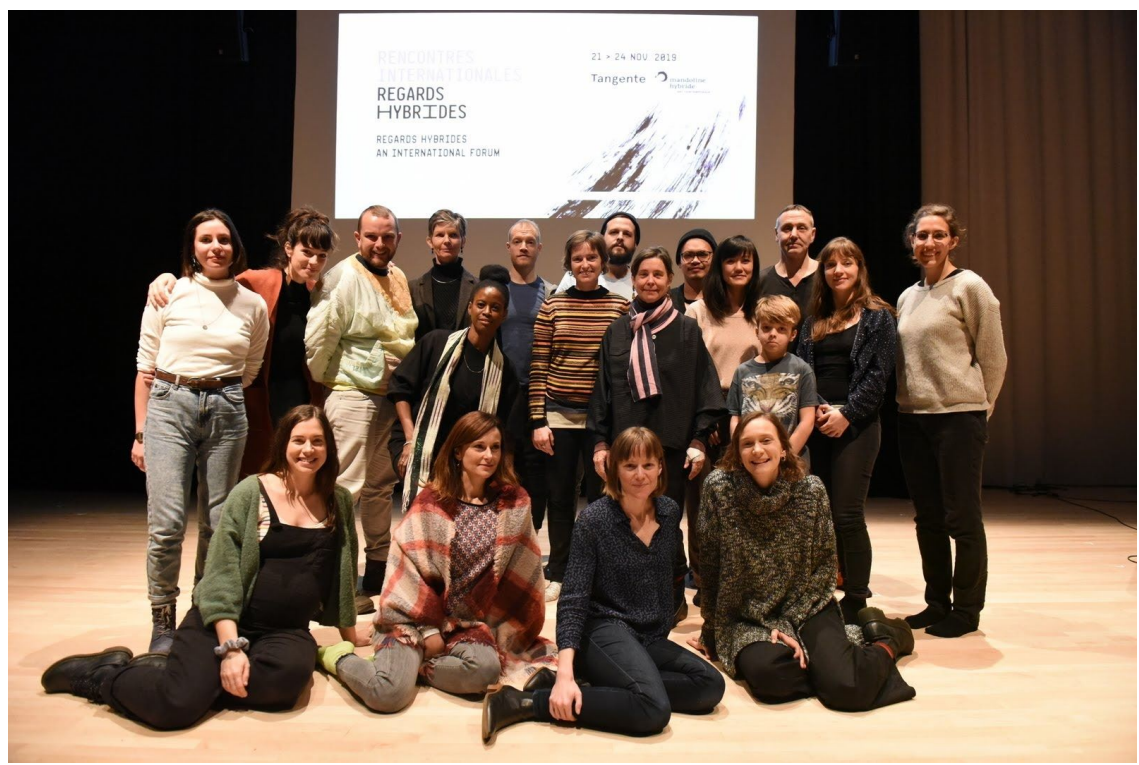

Participants at Regards Hybrides, an International Forum. Photo: Omer Yukseker

In the months that have passed since Regards Hybrides, its importance resonates even more deeply. As our screens become overly populated with creative applications of streaming media, much of it making use of familiar arts-based techniques (Alanna Thain calls it "platform determinism"), it is tempting to frame some of it as screendance. I see movement, esthetic choices, rhythmic editing and some sort of implied meaning leading to a distinctly social message. However, even media production in the service of public awareness quite quickly becomes a trope, subject to overused and at times, hackneyed couplings of form and content. What those involved with Regards Hybrides, an International Forum reminds us is that we have a very full toolkit with which to critically engage mediated images of all kinds, from creation to distribution to analysis. How we deploy these tools is what grants the screendance community a kind of global and artistic citizenship and likewise the responsibilities that come with it in the shifting landscape of the cultures in which we live.

I want to thank all of the presenters noted above whose thoughtful comments both during and after the event illuminated a greater understanding of the ideas in this essay. Thanks also to IJSD editor Marisa Zanotti who helped me clarify some important questions in a long and discursive Skype chat. I also wish to thank Alanna Thain, with whom I spoke briefly at the event but who also generously helped me form some strategies for approaching the idea of archiving intergenerational memory and ways to model "active engagement" in an equally long and rambling on-line conversation. $D R$ 


\section{Author Biography}

Douglas Rosenberg is an artist and a theorist and the author of Screendance:

Inscribing the Ephemeral Image, as well as the editor of the Oxford Handbook of Screendance Studies, both published by Oxford University Press,. He is a founding editor of The International Journal of Screendance and his work for the screen has been exhibited internationally for over 25 years. He has been a long-time advocate of screendance as the founding curator of the International Screendance Festival at the American Dance Festival and as a speaker and organizer of symposia and international workshops. His most recent screendance is CIRCLING, a collaboration for the screen with Sally Gross, an original member of The Judson Dance Theater Group. Rosenberg is a professor in the Art Department at the University of WisconsinMadison.

\section{Notes}

${ }^{1}$ Regards Hybrides, November 21-24, 2019. 'Bodies and Motion Pictures from Scratch: Popular Culture and Low-Tech Screendance’ Artistic director and curator Priscilla Guy (Canada)

http://regardshybrides.com/en/

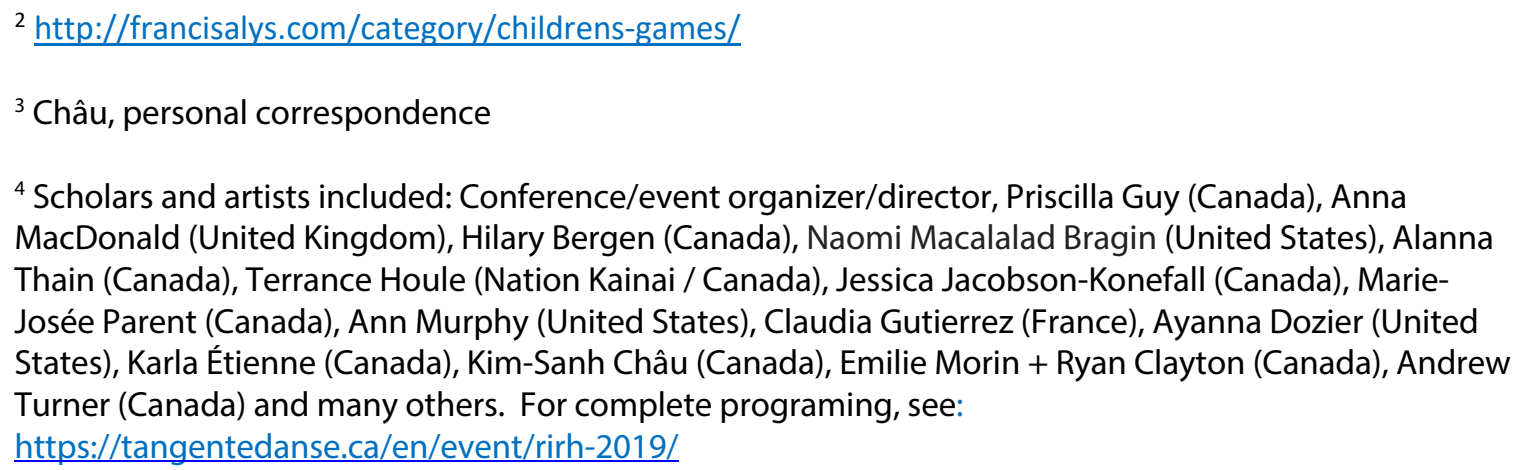

${ }^{5}$ Bergen, personal correspondence

${ }^{6}$ Macdonald, personal correspondence

${ }^{7}$ Dozier, personal correspondence

${ }^{8}$ Thain, personal correspondence

${ }^{9}$ Châu, personal correspondence

${ }^{10}$ Ibid.

${ }^{11}$ Morin + Clayton, personal correspondence

${ }^{12}$ Ibid.

${ }^{13} \mathrm{lbid}$. 